\title{
Dynamics and control of a heat pump assisted extractive dividing-wall column for bioethanol dehydration
}

DOI:

10.1016/j.cherd.2016.12.021

\section{Document Version}

Accepted author manuscript

Link to publication record in Manchester Research Explorer

\section{Citation for published version (APA):}

Patracu, I., Bildea, C. S., \& Kiss, A. A. (2017). Dynamics and control of a heat pump assisted extractive dividingwall column for bioethanol dehydration. Chemical Engineering Research and Design, 119, 66-74.

https://doi.org/10.1016/j.cherd.2016.12.021

\section{Published in:}

Chemical Engineering Research and Design

\section{Citing this paper}

Please note that where the full-text provided on Manchester Research Explorer is the Author Accepted Manuscript or Proof version this may differ from the final Published version. If citing, it is advised that you check and use the publisher's definitive version.

\section{General rights}

Copyright and moral rights for the publications made accessible in the Research Explorer are retained by the authors and/or other copyright owners and it is a condition of accessing publications that users recognise and abide by the legal requirements associated with these rights.

\section{Takedown policy}

If you believe that this document breaches copyright please refer to the University of Manchester's Takedown Procedures [http://man.ac.uk/04Y6Bo] or contact uml.scholarlycommunications@manchester.ac.uk providing relevant details, so we can investigate your claim.

\section{OPEN ACCESS}


1 Dynamics and control of a heat pump assisted extractive dividingwall column for bioethanol dehydration

Iulian Patraşcu, ${ }^{1}$ Costin Sorin Bildea, ${ }^{1}$ Anton A. Kiss, ${ }^{2.3^{*}}$

${ }^{1}$ University "Politehnica” of Bucharest, Polizu 1-7, 011061 Bucharest, Romania

${ }^{2}$ AkzoNobel Research, Development \& Innovation, Process Technology SRG, Zutphenseweg

10, 7418 AJ Deventer, The Netherlands.E-mail:Tony.Kiss@akzonobel.com

${ }^{3}$ Sustainable Process Technology Group, Faculty of Science and Technology, University of

Twente, PO Box 217, 7500 AE Enschede, The Netherlands

*Corresponding author: TonyKiss@gmail.com, Tel: +31 263669420

Keywords

Bioethanol dehydration; process dynamics; process control; integrated design; heat pumps

Highlights

- Highly integrated design leading to challenges in process dynamics and control

- Disturbances in feed flowrate and composition can be effectively rejected

\section{Abstract}

Recently, a novel heat-pump-assisted extractive distillation process taking place in a dividingwall column was proposed for bioethanol dehydration. This integrated design combines three distillation columns into a single unit that allows over $40 \%$ energy savings and low specific energy requirements of $1.24 \mathrm{kWh} / \mathrm{kg}$ ethanol. However, these economic benefits are possible only if this highly integrated system is also controllable to ensure operational availability. This paper is the first to address the challenges related to process dynamics and control of this highly integrated system. After showing the control difficulties associated with the original design owing to thermal unbalance, an efficient control structure is proposed which introduces a by-pass and an additional external duty stream to the side reboiler. The range of the external duty is rather small, about $5 \%$ of the combined duty of the reboilers, but sufficient to stabilize the system by controlling the temperature on the pre-concentration side of the column. Two quality control loops ensures product purity when the system is affected by feed flowrate and composition disturbances. 


\section{1. Introduction}

2 Bioethanol is a renewable fuel produced in largest amounts, by various routes: corn-toethanol, sugarcane-to-ethanol, basic and integrated lignocellulosic biomass-to-ethanol. In all cases, the raw materials are pre-treated and then fermented to yield diluted bioethanol of 512\% concentration (Vane, 2008; Huang et al., 2008; Frolkova and Raeva, 2010). This needs to be further concentrated to $99-99.8 \%$ wt (depending on the standard), in an energy intensive process that involves distillation combined usually with extractive distillation (Kiss and Ignat, 2013). The concentration of diluted streams from fermentation is not an issue related only to ethanol, but a more generic problem encountered in biorefineries (Kiss et al., 2016). Various energy improvements of the distillation process have been proposed for the ethanol separation and purification, such as the use of internally heat-integrated distillation columns (HIDiC) that are based on the vapor recompression principles (Kiss and Olujic, 2014; Ponce et al., 2015). However, the HIDiC technology is hindered by large equipment costs (leading to long payback times) and it is also limited to producing only hydrated ethanol.

Dividing-wall column (DWC) is a proven process intensification distillation technology that can deliver 25-35\% savings in energy and investment costs (Dejanovic et al., 2010; Yildirim et al., 2011; Kiss, 2013). In spite of the integration of two distillation columns into a single shell, DWC proved to be controllable providing that a suitable control scheme is selected based on simple PID or more advanced controllers (Serra et al., 1999; Diggelen et al., 2010; Kiss and Bildea, 2011; Rewagad and Kiss, 2012). The addition of heat pumps to dividingwall column technology was also proposed for various processes but the process dynamics was not investigated (Chew et al., 2014; Luo et al., 2015; Liu et al., 2015; Shi et al., 2015). Using DWC for various processes, including bioethanol dehydration by azeotropic and extractive distillation was proposed by several authors (Bravo-Bravo et al., 2010; Sun et al., 2011; Kiss and Suszwalak, 2012). Later, the control analysis of extractive dividing-wall columns revealed satisfactory controllability properties of such integrated systems (TututiAvila et al., 2014; Zhang et al., 2014).

In a follow-up study, Kiss and Ignat (2012) proposed a novel extractive DWC configuration that integrates the three distillation columns of a classic process - pre-concentration distillation column (PDC), extractive distillation column (EDC), and solvent recovery column (SRC) - into a single unit. On top of this integrated extractive DWC system, Luo et al. (2015) added also a vapor recompression (VRC) heat pump to further increase the energy savings up to $40 \%$ (see Figure 1). This elegant solution was also featured at the joint PSE-2015 \& ESCAPE-25 conference (www.pse2015escape25.dk) among the best contributions in the 
1 process design section. But the authors were also challenged to prove the controllability of such a highly-integrated system. This paper addresses for the first time the challenges related to the process dynamics and control of the proposed integrated heat pump assisted E-DWC.

\section{Problem statement}

The smart combination of heat pumps (e.g. vapor recompression) with extractive dividingwall column (E-DWC) technology offers significant advantages in terms of low total annual costs and major energy savings of about $40 \%$. But the controllability of the process is just as important as the cost savings, considering that the plant must be available and fully operable in order to deliver the expected design savings. The problem is that a more integrated system has less flexibility and fewer degrees of freedom hence being more difficult to control. To solve this problem, we investigate the dynamics of the process and propose a rather simple but effective process control structure that is able to reject common disturbances, within short settling times and low overshooting.

\section{Results and discussion}

Plantwide control deals with the strategy of solving the dynamic problems of a full process, under the production (rate and quality) and safety constrains, while minimizing the costs. In this work, an efficient control structure is developed by addressing these tasks of plantwide control. To achieve this goal, dynamic simulations (carried out in Aspen Dynamics) were used to understand the dynamics of the process and to prove the effectiveness of the proposed control structures. The starting point is the VRC assisted E-DWC design proposed by Luo et al. (2015), which achieves $40 \%$ energy savings compared to the conventional separation sequence. Note that further energy integration could be attempted by using the product streams for feed pre-heating. However, as there is no liquid flow from the main column to the pre-fractionator, the feed stream acts as reflux. Therefore, feeding below the boiling point improves separation efficiency. Figure 1 presents for details of the VRC assisted E-DWC, including the mass and energy balance. Steady state temperature and composition profiles are shown in Figure 2. The reader is referred to the original paper (Luo et al., 2015) for more details concerning the principle of operation and the efficiency of the system.

\subsection{Process dynamics}

The original Aspen Plus steady state simulation was exported to Aspen Dynamics. The simulation consists of two separate RADFRAC models which correspond to the PDC and 
1 EDC-SRC sides of the dividing-wall column and are inter-connected by vapor and liquid

2 streams. The dynamic simulation model is presented in Figure 3, which includes the setpoint 3 of the main controllers.

4 The safety of a process is typically achieved by a combination of inherent safe design, safety relief valves and instrument protective functions. The process control system supports safety by controlling the liquid levels and gas pressures, thus ensuring that all the material is contained within the process boundaries. The default inventory controllers provided by Aspen Plus / Aspen Dynamics are:

- Level of the PDC sump, by manipulating the bottoms flow rate. According to the steady state boilup ratio $V / B$, a fraction of this stream is withdrawn as product, while the rest is sent to the side reboiler.

- Level of the EDC-SRC sump, by manipulating the bottoms flow rate.

- Pressure of the PDC column (top), by manipulating the vapor distillate rate. Note that this controller, required by the flow-driven dynamic simulation, is not part of the practical implementation where the pressures above the top tray of the PDC and on the EDC-SRC side are equal.

- Pressure of the EDC-SRC column (top), by manipulating the vapor distillate rate.

Some basic changes were made to the dynamic simulation exported by Aspen Plus:

- The flow rate of solvent entering the EDC-SRC column was set on flow control. The solvent make-up becomes the manipulated variable in a level control loop.

- A heat exchanger was added to allow controlling the temperature of the solvent entering the EDC-SRC column. The duty of this heat exchanger is nearly zero at design condition, but changes when the system is affected by disturbances.

- A vapor-split controller was added. This controller is not part of the practical implementation, but is necessary to ensure that the vapor split remains at the design value in the flow-driven dynamic simulation.

- A compressor-outlet pressure controller was added. By manipulating the compressor brake-power, the pressure of the compressed vapor is kept at the design value. The practical implementation of controlling the outlet pressure and flow is briefly described in next section.

After implementing the basic inventory control, the simulation can be run. Starting from the steady state, as long as the system is not disturbed, the process variables (flow rates, temperatures, pressures) stay at their nominal values. However, the simulation breaks for any 
small disturbances. Quality control loops were added, as follows:

- A temperature controller was added on the condensate stream.

- A temperature controller was added in the EDC-SRC. Temperature on stage 33 (the most sensitive tray) is controlled by the EDC-SRC reboiler duty.

After these changes, the simulation is successful as long as it starts from the steady state and no disturbance is introduced. However, the simulation still breaks for any small increase of the feed rate, which shows that the operating point is unstable. What happens is the following. Increasing the flow rate of PDC feed (cold liquid) leads to a lower vapor flow rate along PDC. As a result, the pressure drops and less vapor is fed to the EDC-SRC section (the PDC pressure controller closes the vapor distillate valve). The pressure on the EDC-SRC section drops and the EDC-SRC pressure controller decreases the EDC-SRC vapor distillate rate. Then, less heat is transferred in the (heat-integrated) side reboiler, followed by further decrease of the vapor flow rate along the PDC. Simultaneously, more EG is found in the bottom section of the EDC-SRC which leads to further temperature increase (despite the lower pressure). The SRC-EDC temperature controller reacts and decreases the reboiler duty, leading to an additional reduction of the vapor flow along the EDC-SRC section (and therefore to further decrease of the SRC-EDC vapors distillate flow). Clearly, an appropriate control structure is required.

The key to stabilizing the system is adding a small duty to the last stage of the PDC column. This duty can then be used as new manipulated variable in a control loop which ensures that the vapor flow rate from the PDC to the SRC-EDC side is constant when the system is affected by disturbances. When the valve-position controller VPC (Figure 3) is added, feed flow rate and composition disturbances can be introduced without affecting the stability of the process. However, the control structure shown in Figure 3 is not able to maintain the quality of the products, namely the purity of the water and ethanol streams. Moreover, measuring the flow rate of the vapor going from the PDC to the SRC-EDC side is difficult in practice. Dynamic simulations also reveal that the solvent feed and PDC bottoms heat exchangers require heating or cooling, depending on the disturbance. Therefore, the control structure presented in Figure 3 is further refined, as explained in the next section.

\subsection{Process control}

As the original design of the VRC assisted E-DWC has control difficulties associated with the thermal unbalance, we propose here a novel efficient control structure that introduces an additional duty stream to the side reboiler. The range of the additional duty is rather small, 
1 about $5 \%$ of the combined duty of the reboilers, but this is sufficient to counteract the possible thermal unbalance. Moreover, the design changes and additional controllers ensures the quality of the water and ethanol product streams.

4 Figure 4 shows the control structure for the VRC assisted E-DWC. For convenience, the setpoint of several controllers are included, while detailed information about controller settings can be found in Table 1. The production rate is set by changing the setpoint of the flow controller manipulating the feed stream flow rate. A ratio controller ensures that the amount of solvent used (make-up and recycle stream) is proportional to the feed flowrate. This ratio is set by a quality controller which achieves constant mass fraction of water impurity in the ethanol product. The temperature of the solvent added to the E-DWC unit is controlled by a split range setup, in which one of the heat exchangers cools-down or heats-up the solvent stream, as required. The compressor is operated at constant outlet pressure - the pressure at which the valve on the outlet line opens - and variable flow rate, which is achieved by means of an internal recycle or other means. The duty of the PDC (external) reboiler is provided by a fraction of the compressed vapors (about $94 \%$ at design conditions) and by hot utility. The external duty provided by the hot utility is used to control the temperature on the PDC side of the dividing-wall column. When the tuning of this loop is sufficiently aggressive (large gain, small integral time), the system is stabilized. The "valveposition control' (VPC) loop ensures both rapid response to disturbances and energy efficiency. Thus, when higher duty is required by the PDC temperature controller, the flow rate of hot utility is increased. This has a fast effect on the controlled variable. Afterwards, the VPC controller gradually increases the flow rate of compressed vapors passing through the reboiler (by-pass fraction is reduced), until the utility flow rate returns to its design / set point value. The set point of the PDC temperature controller is given, in cascade fashion, by a quality controller keeping constant the mass fraction of ethanol impurity in the water product stream. Note that the dynamics of the concentration transducers (measurements) on the ethanol and water streams was properly modelled including 1 minute sampling interval and 1 minute dead-time.

In practice, the feed contains small amounts (about $0.1 \%$ wt.) of dissolved $\mathrm{CO} 2$, which have to be removed from the system. To this end, a small purge stream from the reflux drum could be used as manipulated variable, in a pressure control loop (Loy et al., 2015; Batista et al., 2012). Table 1 provides the controller tuning parameters. The control loops were tuned by a simple version of the direct synthesis method (Luyben and Luyben, 1997), according to which, the desired closed-loop response for a given input is specified. With the model of the process 
1 known, the required form and the tuning of the feedback controller are then back-calculated.

2 For all controllers, the acceptable control error $\left(\Delta \varepsilon_{\max }\right)$ and the maximum available control action $\left(\Delta u_{\max }\right)$ were specified. Afterwards, the controller gain (expressed in engineering units) was calculated as $K_{\mathrm{c}}=\Delta u_{\max } / \Delta \varepsilon_{\max }$ and translated into percentage units. First order open-loop models were assumed, in order to calculate the integral time of the pressure, temperature and concentration control loops (Bildea and Kiss, 2011). As rough evaluations of the process time constants $\tau, 12 \mathrm{~min}, 20 \mathrm{~min}$ and $40 \mathrm{~min}$ were used, respectively. It can be shown (Luyben and Luyben, 1997) that the direct synthesis method requires that the reset time of a PI controller is equal to the time constant of the process $\left(\tau_{\mathrm{i}}=\tau\right)$. For the level controllers, a rather large reset time $\tau_{\mathrm{i}}=60 \mathrm{~min}$ was chosen, as no tight control is required. When the PDC temperature control loop is sufficiently fast, the system is stabilized and disturbances can be successfully rejected. To tune the concentration controllers, the ultimate gain and the period of oscillations at stability limit were found using the ATV (Auto Tuning Variation) method. These values were further used to calculate the controller parameters according to Tyreus-Luyben settings (Luyben and Luyben, 1997).

Figure 5 and Figure 6 show the dynamic response of the system for feed flow rate disturbances. Starting from the steady state, the feed rate is ramped up by $10 \%$ (from $t=2 \mathrm{~h}$ to $t=4 \mathrm{~h}$ ), brought back to the initial value (at $t=12 \mathrm{~h}$ ), decreased by $10 \%$ (at $t=22 \mathrm{~h}$ ), and returned again to the initial value (at $t=32 \mathrm{~h}$ ). Both the ethanol and water flow rates change accordingly to their feed rate and reach their new steady state values in a rather short time with almost no overshooting (Figure 5, left). It is remarkable that the composition of the ethanol and water stream products remains practically unchanged (Figure 5 right, where the mass fraction of solvent in water is shown, as this variable is not measured / controlled). Figure 6 shows the key internal variables, for the same scenario. The various internal flow rates follow the change of the feed rate (plot a). The ethanol purity is maintained by changing the solvent/feed ratio (plot $\mathrm{b}$ ). When the feed rate increases (from $t=2 \mathrm{~h}$ to $t=12 \mathrm{~h}$ ), higher side-reboiler duty is required. This is achieved by increasing the external duty (plot c) and by reducing the by-pass around the side-reboiler (plot d). Note that when lower duty is required (from $t=22 \mathrm{~h}$ to $t=32 \mathrm{~h}$ ), this is achieved by increasing the by-pass, while the external duty remains at the minimum value of $2 \mathrm{GJ} / \mathrm{h}$.

31 The system can also withstand larger feed flow rate disturbances, for example $+/-20 \%$, if they occur as ramp with the maximum slope of about 5\% / hour. Moreover, a larger range of the external duty is required $(0-16 \mathrm{GJ} / \mathrm{h})$. Although this seems to be a limitation of the 
1 controllability of this highly integrated system, fast changes of the feed rate (for example in 2 the form of step signals) are not likely to be encountered in practice.

3 Figure 7 and Figure 8 show the dynamic response to various changes of feed ethanol concentration, from the initial value of $10 \%$ wt. to $12 \%$ wt., and $8 \%$ wt., similarly to the previously described scenario. The flowrates of ethanol and water products follow the amounts existing in the feed (Figure 7 - left). The changes in the concentration of impurities (solvent in water, and water in ethanol) are quite minor and the system stabilizes shortly (Figure 7 - right). The key internal variables shown in Figure 8 have limited variations, and return to their initial values when the disturbance is removed.

Figure 9 and Figure 10 show dynamic simulation results for changing the setpoint of the ethanol concentration controller from the initial value of $99.8 \% \mathrm{wt}$ to $99.5 \% \mathrm{wt}$ (at $t=2 \mathrm{~h}$ ), and to $99 \%$ wt (at $t=12 \mathrm{~h}$ ), after which the setpoint is brought back to the initial value in two steps (at $t=22 \mathrm{~h}$ and $t=32 \mathrm{~h}$ ). The setpoint changes are implemented as ramp signals, over 8hour period. The product flow rates change according to the mass balance (Figure $9-$ left), while the ethanol concentration follows it setpoint (Figure 9 - right). The internal variables have limited changes (Figure 10) and return to initial values once the disturbance is removed. Tututi-Avila et al. (2014) analyzed the control properties of a conventional extractive dividing-wall column used for ethanol dehydration, where the feed stream is a concentrated ethanol solution (93\%wt). The control structure involved conventional temperature, pressure and level control loops. Use of the vapor split as manipulated variable in a temperature control loop was necessary to properly reject step feed flow rate and composition disturbances, product purities returning close to their specifications in about $1.5 \mathrm{~h}$. For most disturbances, the VRC assisted E-DWC is equally fast. However, the dynamics is slower when the ethanol feed concentration decreases, the new steady state being achieved in about 5 hours. By using concentration controllers, the control structure of the VRC assisted E-DWC achieves better composition control, without the need of vapor split manipulation. In contrast to the conventional E-DWC system, the VRC assisted E-DWC cannot withstand step disturbances, due to higher degree of integration.

\section{Conclusions}

Integrated processes combining vapor recompression with dividing-wall column technology have more interactions of variables and fewer degrees of freedom as compared to classic DWC systems. This makes it challenging to control and questions the expected benefits. 
1 In particular, the system is unstable even when appropriate basic inventory (level and 2 pressure) controllers are provided. The reason is the positive feedback due to vaporrecompression: decrease of the pre-fractionator temperature leads to lower flow rate of the recompressed vapor, which results in less heat being transferred in the side reboiler, and further temperature decrease. Some design changes are necessary to provide the manipulated variables necessary for stabilizing the system. Thus, the side reboiler has an additional external duty, used for pre-fractionator temperature control. Moreover, only a fraction of the recompressed vapor is used for heating the side reboiler. Manipulating the by-pass provides additional heat when needed, but also ensures that the external duty is not shut down and is kept to a minimum value. Concentration measurements are necessary to achieve good quality control of the ethanol and water streams.

An effective control structure that achieves the control objective is the main result of this study, which is the first to prove the controllability of vapor recompression assisted extractive DWC. The system is robust to ramp feed rate and feed composition disturbances and to ramp changes of ethanol purity setpoint. As step changes are not tolerated, this study provides a clear warning to process and control engineers that such changes should be implemented in a slow fashion.

\section{Acknowledgement}

Financial support of the European Commission through the European Regional Development Fund and of the Romanian state budget, under the grant agreement 155/25.11.2016 (Project POC P-37-449, acronym ASPiRE) is gratefully acknowledged.

\section{References}

1. Batista F. R. M., Follegatti-Romero L. A., Bessa L. C. B. A., Meirelles A. J. A., Computational simulation applied to the investigation of industrial plants for bioethanol distillation, Computers and Chemical Engineering, 46 (2012), 1-16.

2. Bildea C. S., Kiss A. A., Dynamics and control of a biodiesel process by reactive absorption, Chemical Engineering Research and Design, 89 (2011), 187-196.

3. Bravo-Bravo C., Segovia-Hernández J.G., Gutiérrez-Antonio C., Duran A.L., BonillaPetriciolet A., Briones-Ramírez A., Extractive dividing wall column: Design and optimization, Industrial \& Engineering Chemistry Research, 49 (2010), 3672-3688.

4. Chew J. M., Reddy C. C. S., Rangaiah G. P., Improving energy efficiency of dividing- 
wall columns using heat pumps, Organic Rankine Cycle and Kalina Cycle, Chemical Engineering and Processing: Process Intensification, 76 (2014), 45-59.

5. Dejanović I., Matijašević L., Olujić Ž., Dividing wall column - A breakthrough towards sustainable distilling, Chemical Engineering and Processing, 49 (2010), 559-580.

6. Diggelen R. C. van, Kiss A. A., Heemink A. W, Comparison of control strategies for dividing-wall columns, Industrial \& Engineering Chemistry Research, 49 (2010, 288-307.

7. Frolkova A. K., Raeva V. M., Bioethanol dehydration: State of the art, Theoretical Foundations of Chemical Engineering, 44 (2010), 545-556.

8. Huang H. J., Ramaswamy S., Tschirner U. W., Ramarao B. V., A review of separation technologies in current and future biorefineries, Separation and Purification Technology 62 (2008), 1-21.

9. Kiss A. A., Bildea C. S., A control perspective on process intensification in dividing-wall columns, Chemical Engineering and Processing, 50 (2011), 281-292.

10. Kiss A. A., Suszwalak D. J-P. C., Enhanced bioethanol dehydration by extractive and azeotropic distillation in dividing-wall columns, Separation \& Purification Technology, 86 (2012), 70-78.

11. Kiss A. A., Ignat R. M., Innovative single step bioethanol dehydration in an extractive dividing-wall column, Separation \& Purification Technology, 98 (2012), 290-297.

12. Kiss A. A., Ignat R. M., Optimal economic design of a bioethanol dehydration process by extractive distillation, Energy Technology, 1 (2013), 166-170.

13. Kiss A.A., Advanced distillation technologies - Design, control and applications. Wiley, Chichester, UK, 2013.

14. Kiss A. A., Olujic Z., A review on process intensification in internally heat-integrated distillation columns, Chemical Engineering and Processing: Process Intensification, 86 (2014), 125-144.

15. Kiss A. A., Lange J. P., Schuur B., Brilman D. W. F., van der Ham A. G. J., Kersten S. R. A., Separation technology - Making a difference in biorefineries, Biomass and Bioenergy, 95 (2016), 296-309.

16. Liu Y., Zhai J., Li L., Sun L., Zhai C., Heat pump assisted reactive and azeotropic distillations in dividing wall columns, Chemical Engineering and Processing: Process Intensification, 95 (2015), 289-301.

17. Loy Y. Y., Lee X. L., Rangaiah G. P., Bioethanol recovery and purification using extractive dividing-wall column and pressure swing adsorption: An economic comparison after heat integration and optimization, Separation and Purification Technology, 149 
(2015), 413-427.

18. Luo H., Bildea C. S., Kiss A. A., Novel heat-pump-assisted extractive distillation for bioethanol purification, Industrial \& Engineering Chemistry Research, 54 (2015), 22082213.

19. Luyben W. L., Luyben M. L., Essentials of process control, McGraw-Hill, US, 1997.

20. Ponce G. H. S. F., Alves M., Miranda J. C. C., Maciel Filho R., Wolf Maciel M. R., Using an internally heat-integrated distillation column for ethanol-water separation for fuel applications, Chemical Engineering Research and Design, 95 (2015), 55-63.

21. Rewagad R. R., Kiss A. A., Dynamic optimization of a dividing-wall column using model predictive control, Chemical Engineering Science, 68 (2012), 132-142.

22. Serra M., Espuña A., Puigjaner L., Control and optimization of the divided wall column, Chemical Engineering and Processing, 38 (1999), 549-562.

23. Shi L., Huang K., Wang S.-J., Yu J., Yuan Y., Chen H., Wong D. S. H., Application of vapor recompression to heterogeneous azeotropic dividing-wall distillation columns, Industrial \& Engineering Chemistry Research, 54 (2015), 11592-11609.

24. Sun L. Y., Chang X. W., Qi C. X., Li Q. S., Implementation of ethanol dehydration using dividing-wall heterogeneous azeotropic distillation column, Separation Science and Technology, 46 (2011), 1365-1375.

25. Tututi-Avila S., Jiménez-Gutiérrez A., Hahn J., Control analysis of an extractive dividingwall column used for ethanol dehydration, Chemical Engineering and Processing: Process Intensification, 82 (2014), 88-100.

26. Vane L. M., Separation technologies for the recovery and dehydration of alcohols from fermentation broths, Biofuels, Bioproducts and Biorefining, 2 (2008), 553-588.

27. Yildirim O., Kiss A. A., Kenig E. Y., Dividing wall columns in chemical process industry: A review on current activities, Separation \& Purification Technology, 80 (2011), 403-417.

28. Zhang H., Ye Q., Qin J., Xu H., Li N., Design and control of extractive dividing-wall column for separating ethyl acetate-isopropyl alcohol mixture, Industrial \& Engineering Chemistry Research, 53 (2014), 1189-1205. 


\section{$1 \quad$ Tables}

2

3 Table 1. Controller tuning parameters

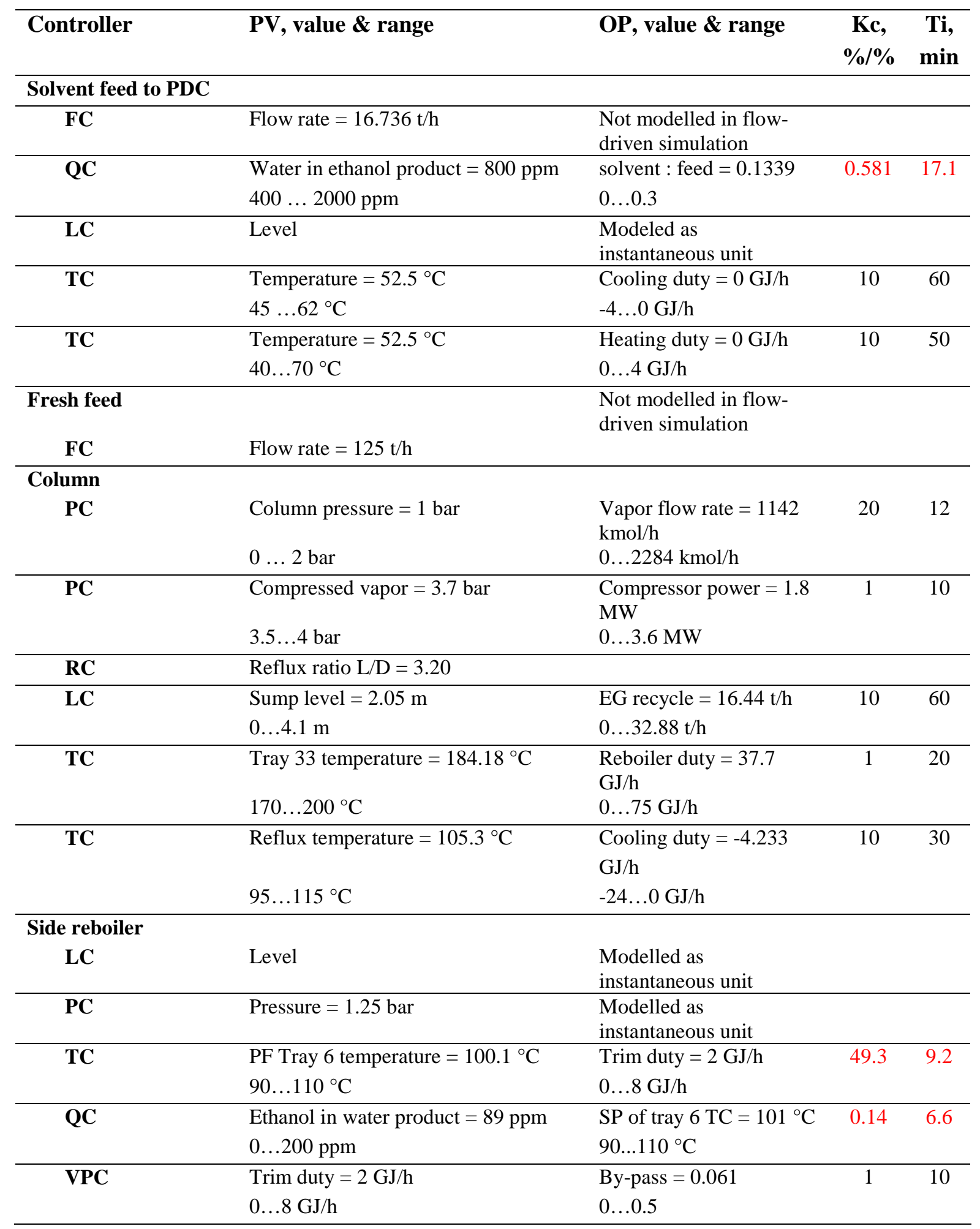


$1 \quad$ Figure captions (auto-updated)

2

3 4

Figure 1. Flowsheet of the VRC assisted extractive-DWC for bioethanol dehydration

Figure 2. Steady state temperature and liquid phase composition profiles of pre-fractionator (dashed lines) and SRC-EDC (continuous lines)

Figure 3. Dynamic simulation model of the VRC assisted extractive-DWC for bioethanol dehydration including the control loops necessary for stabilizing the process

Figure 4. Control structure of the VRC assisted E-DWC for bioethanol dehydration

Figure 5. Dynamic response of products flow rate and purity, for $\pm 10 \%$ disturbance of feed flow rate

Figure 6. Key internal variables for $\pm 10 \%$ flow disturbance. a) Flow rates; b) Ethanol product composition controller; c) Prefractionator temperature controller; d) Side-reboiler external duty controller (VPC)

Figure 7. Dynamic response of products flow rate and purity, for $+/-2 \%$ disturbance of feed concentration

Figure 8. Key internals variables for $+/-2 \%$ disturbance of feed concentration a) Flow rates; b) Ethanol product composition controller; c) Prefractionator temperature controller; d) Sidereboiler external duty controller (VPC)

Figure 9. Dynamic response of products flow rate and purity, for 99.8 to $99.0 \%$ wt range disturbances of ethanol product purity

Figure 10. Key internals variables for 99.8 to $99.0 \%$ wt range disturbance of ethanol product purity. a) Flow rates; b) Ethanol product composition controller; c) Prefractionator temperature controller; d) Side-reboiler external duty controller (VPC) 


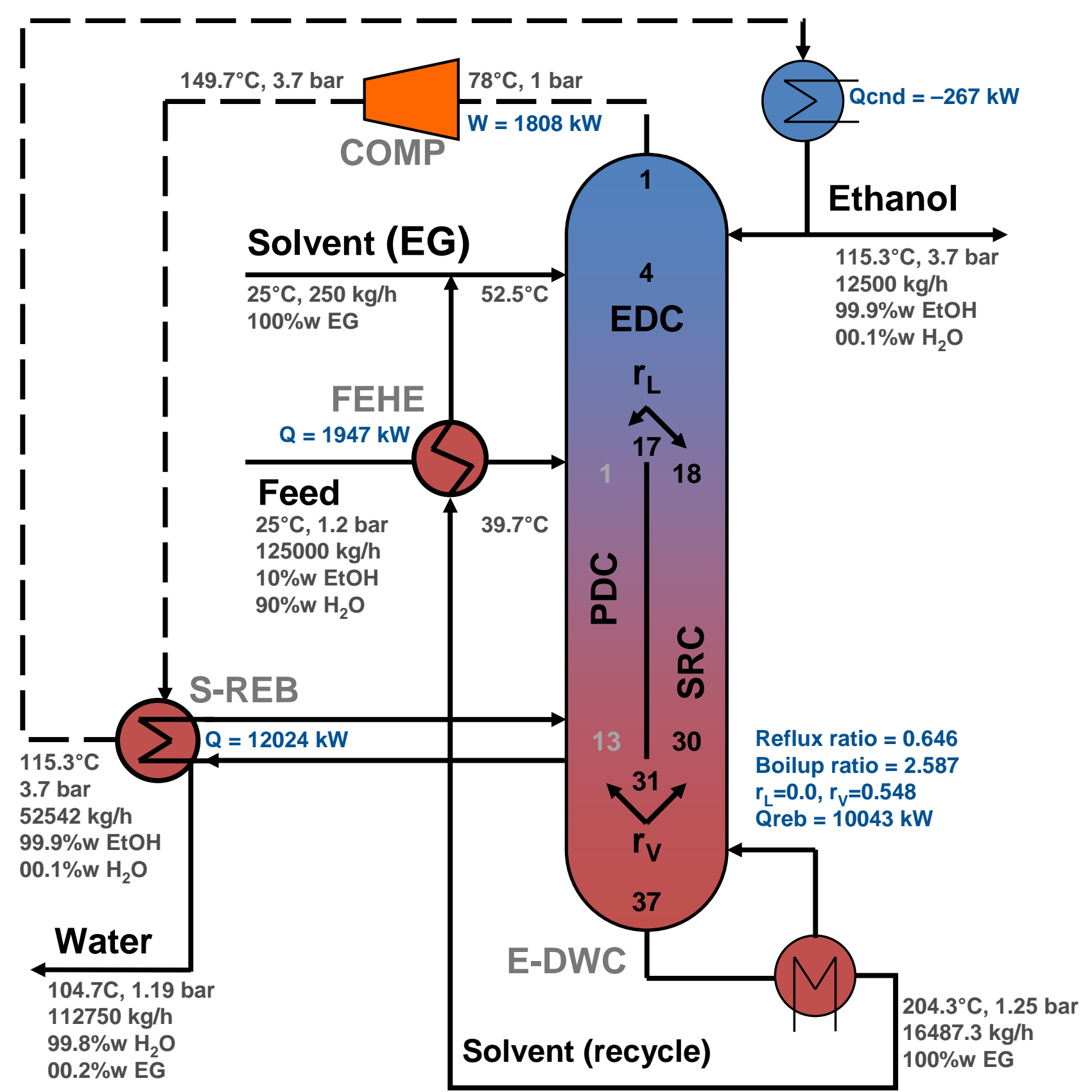



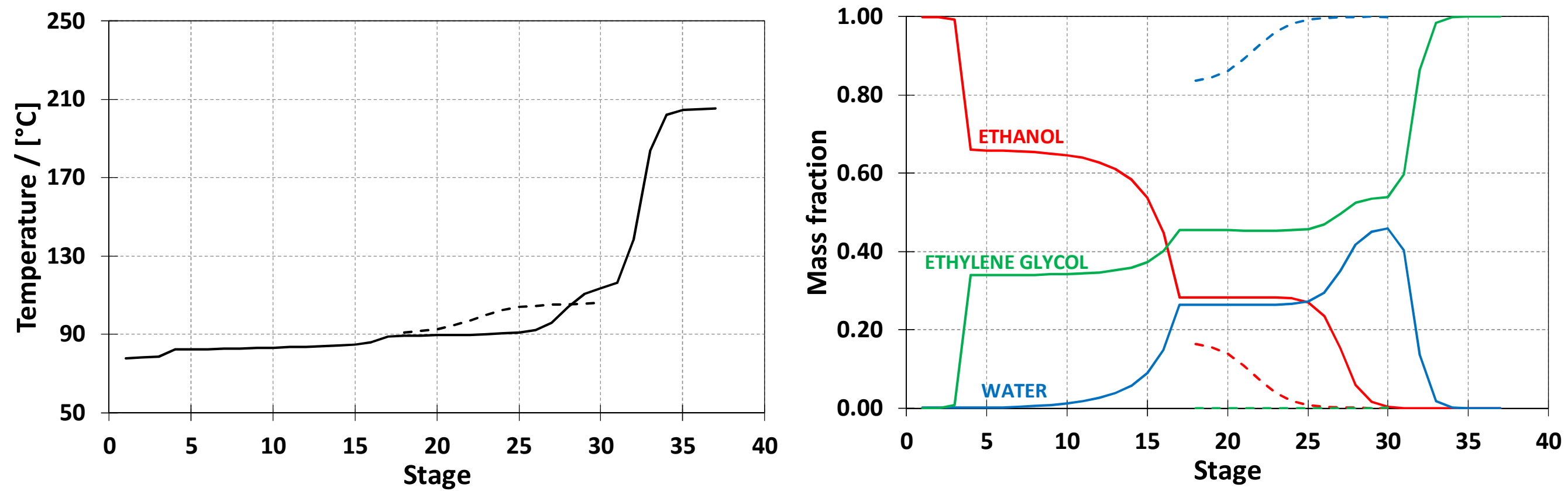

Figure 2 


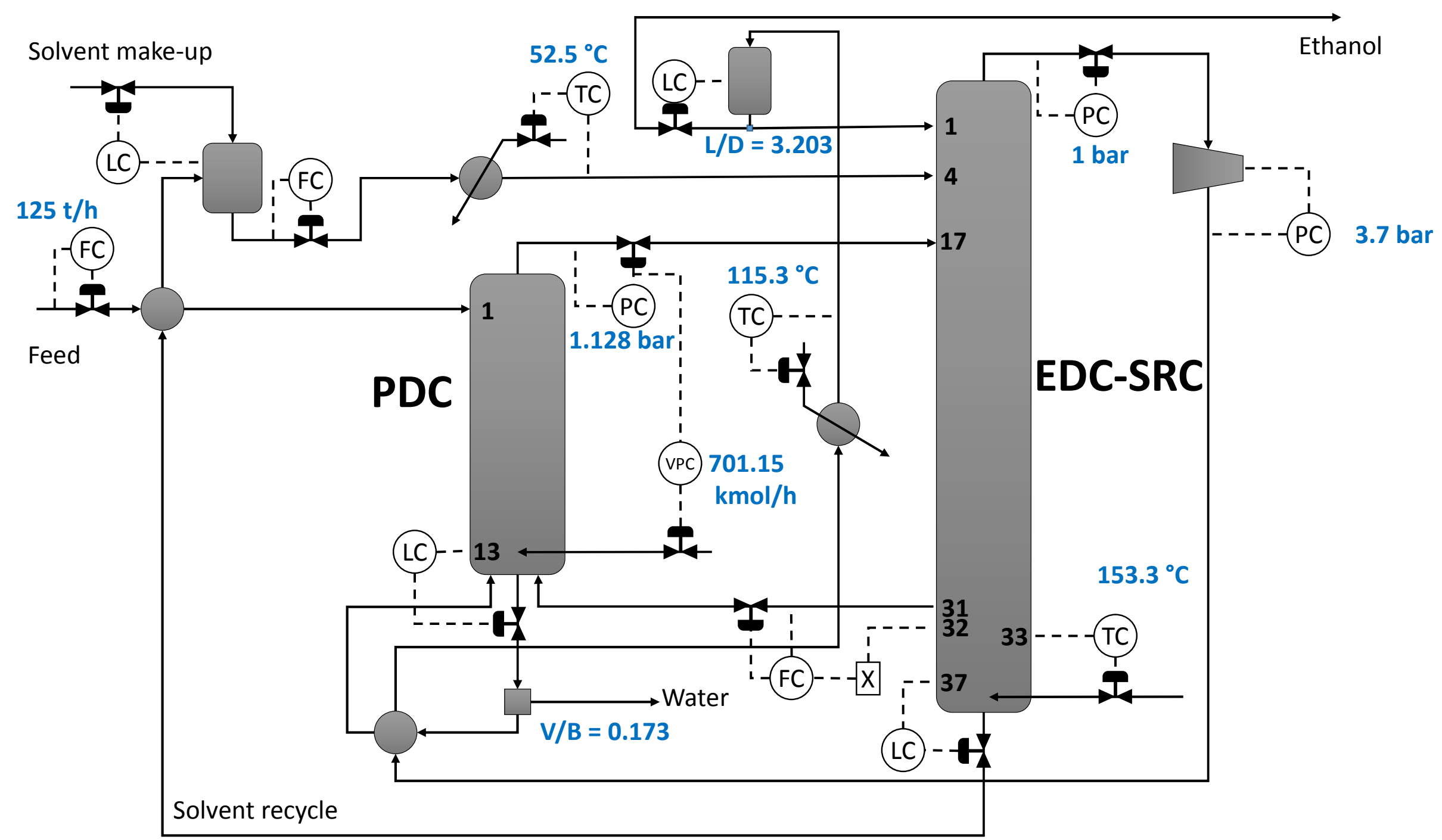

Figure 3 


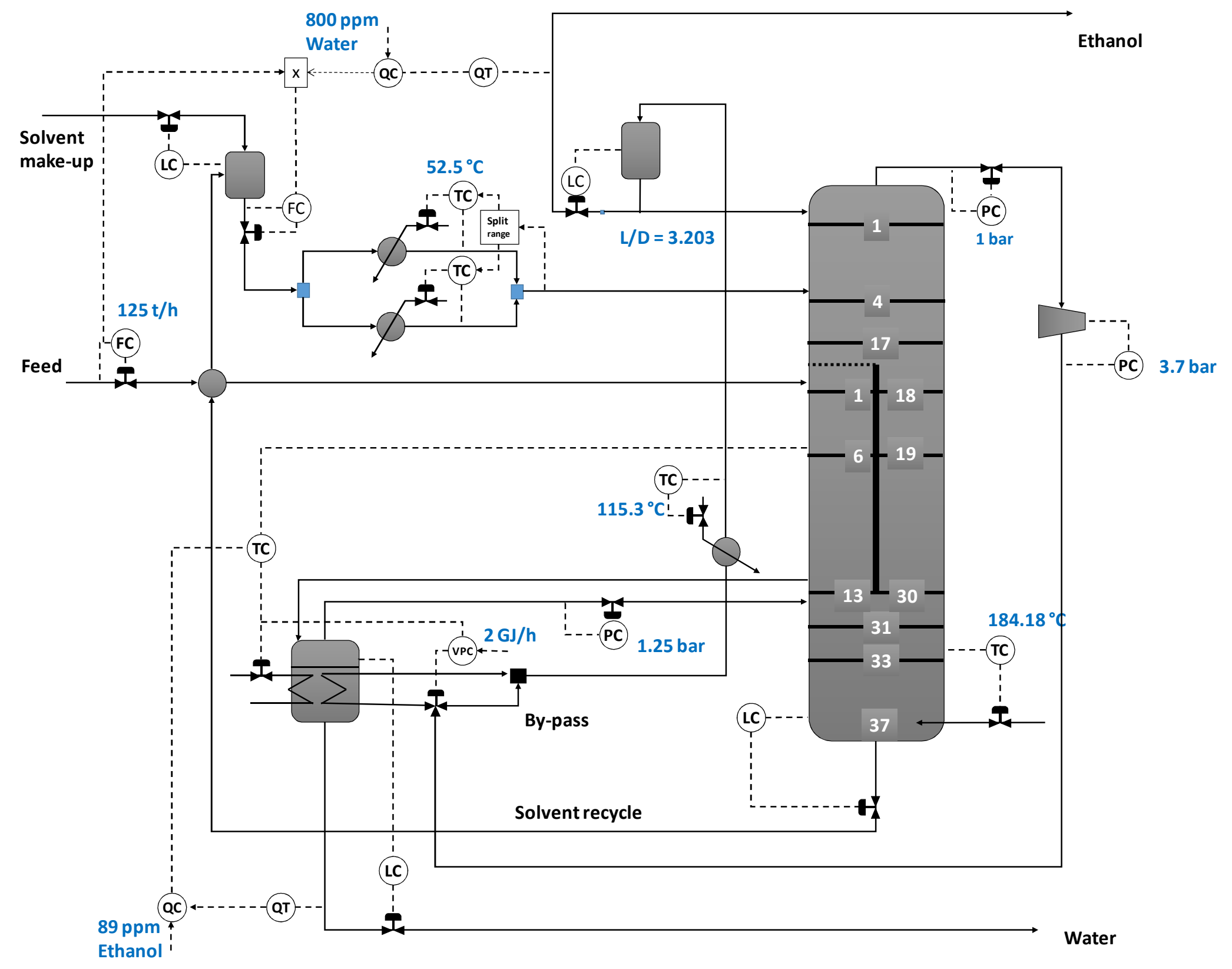

Figure 4 

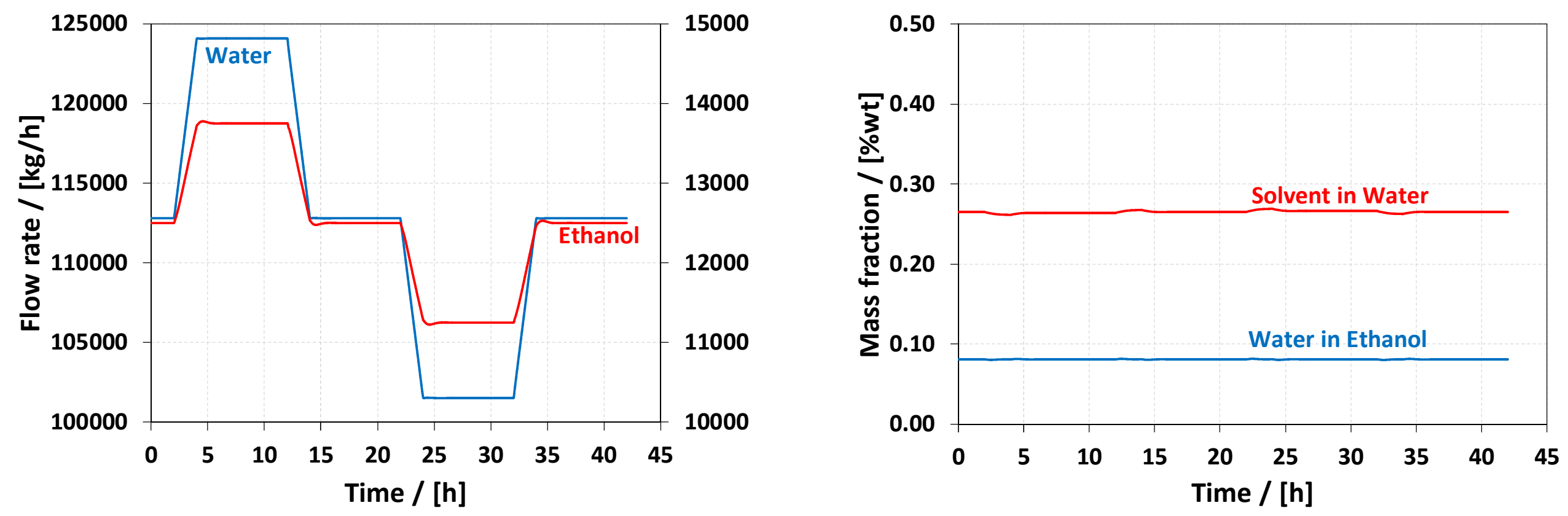

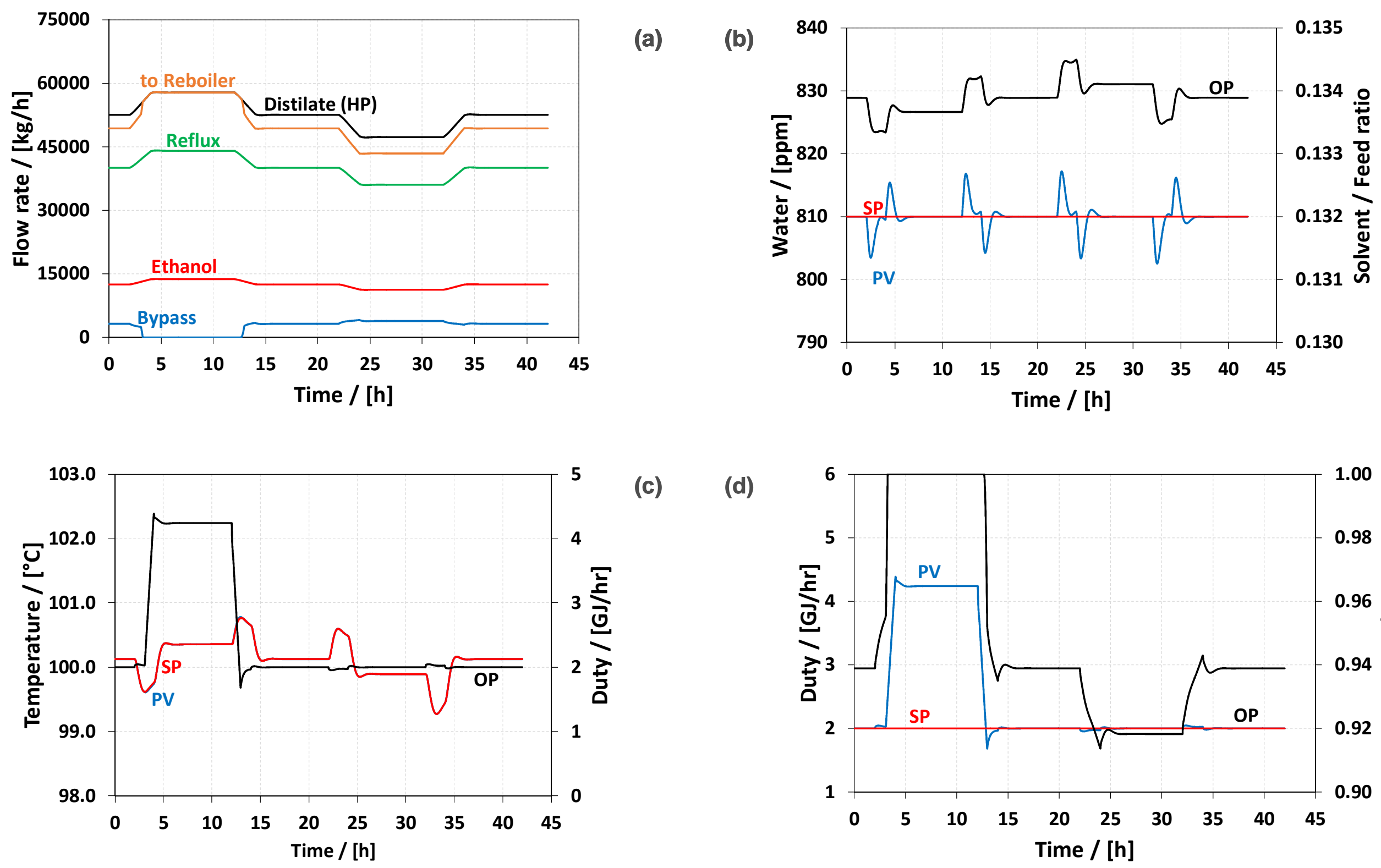

(c)

(d)

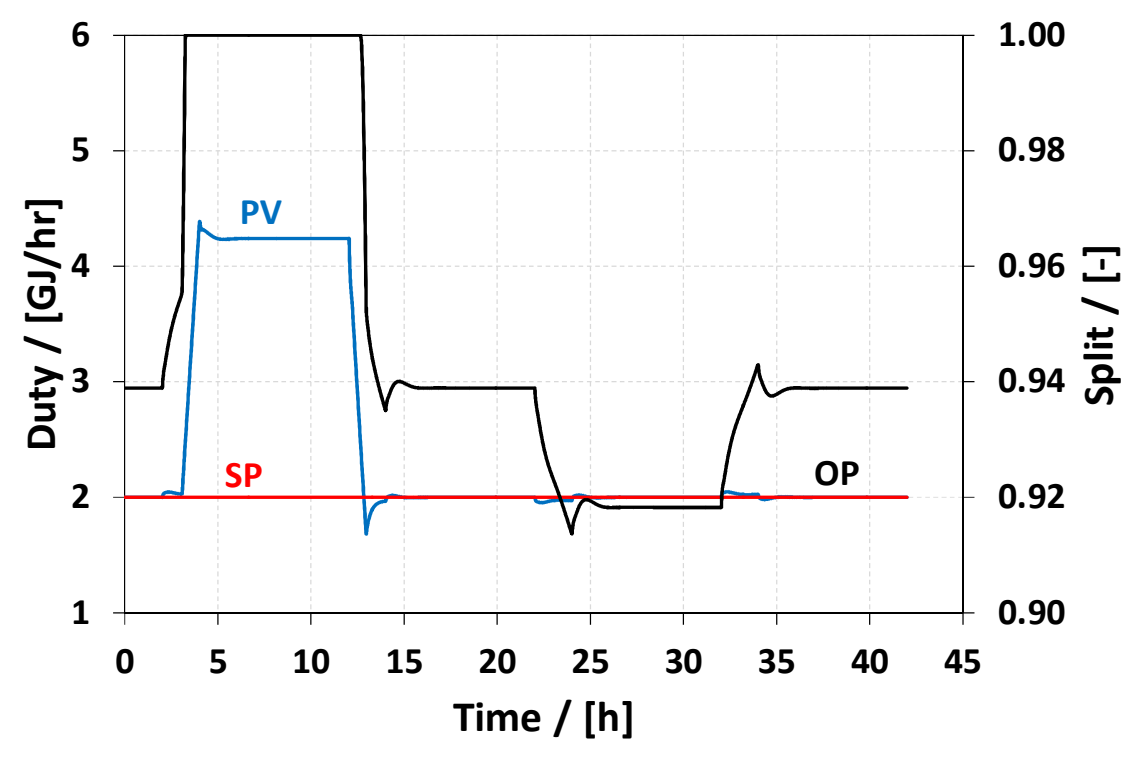

Figure 6 

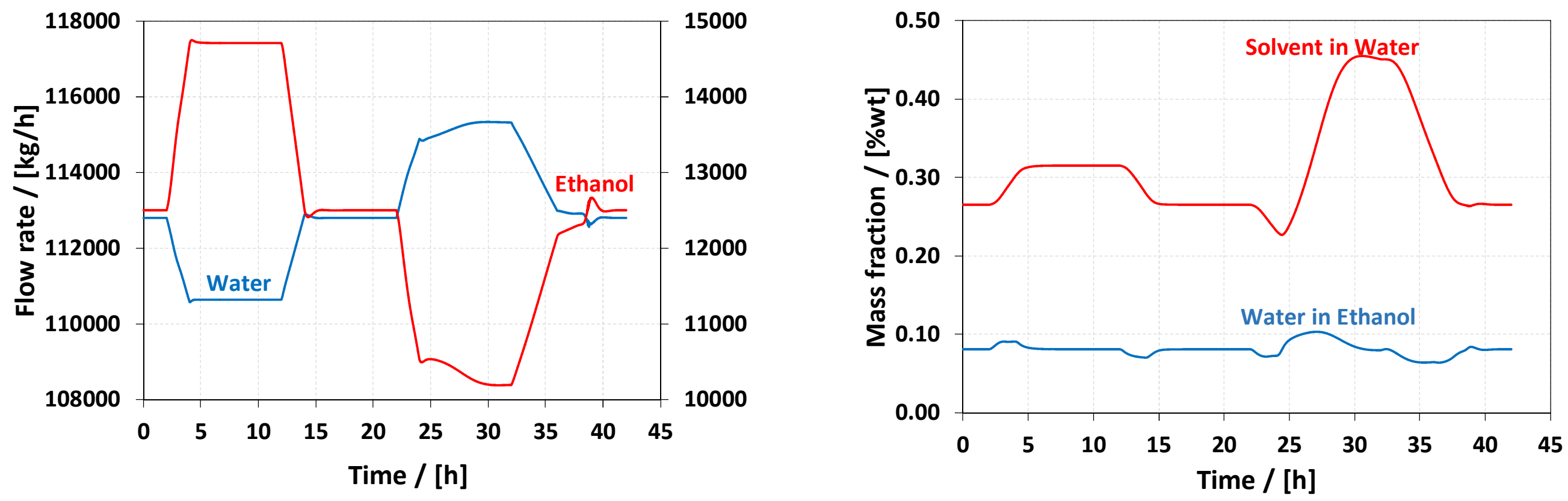


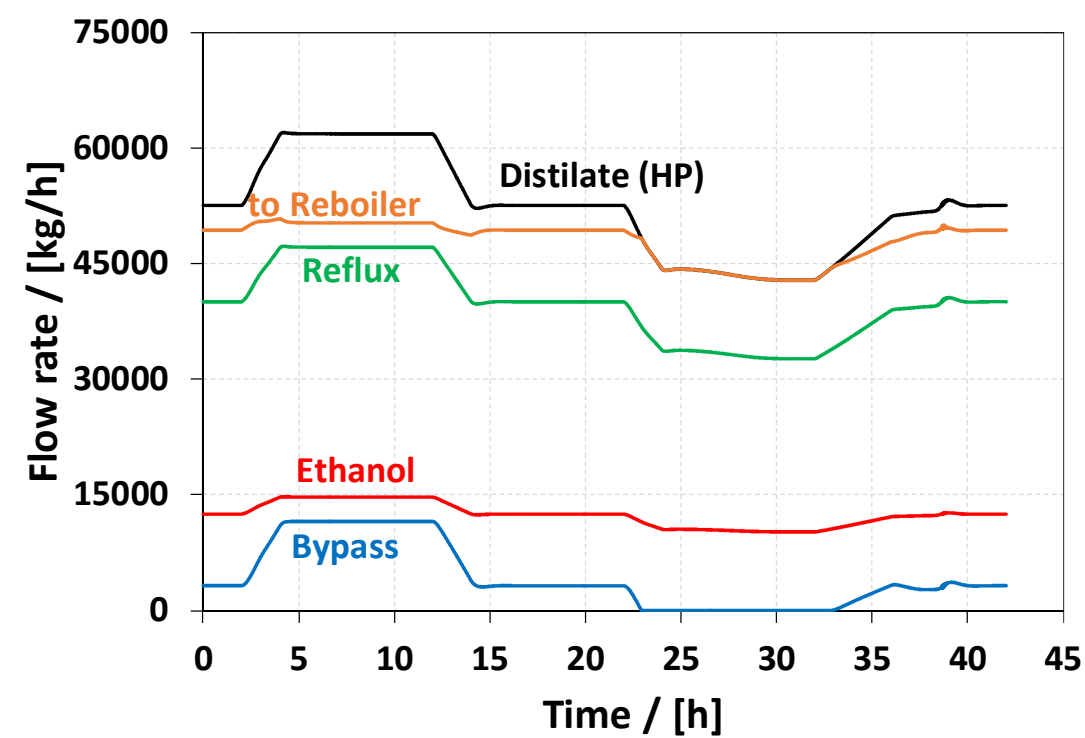

(a)
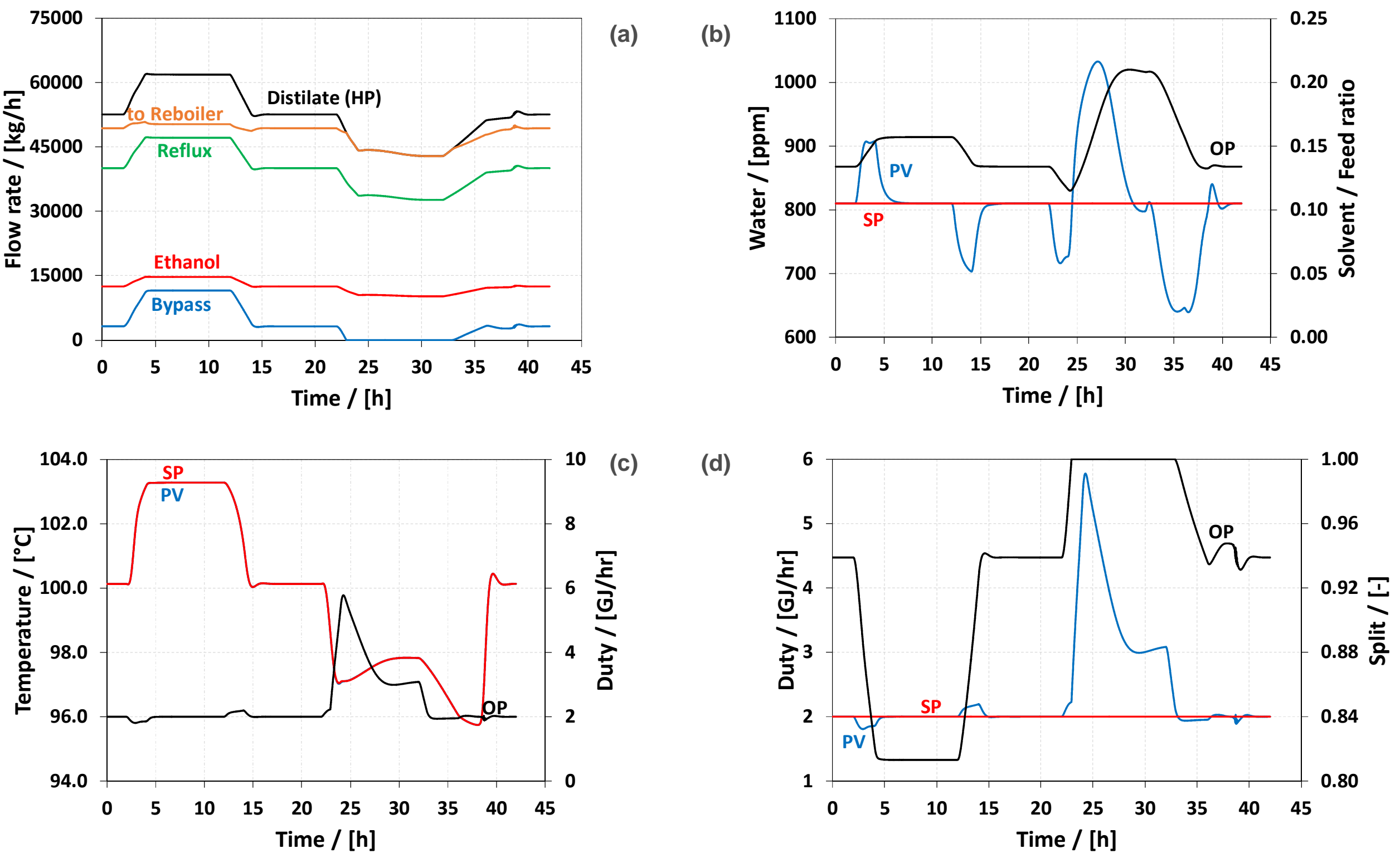

Figure 8 

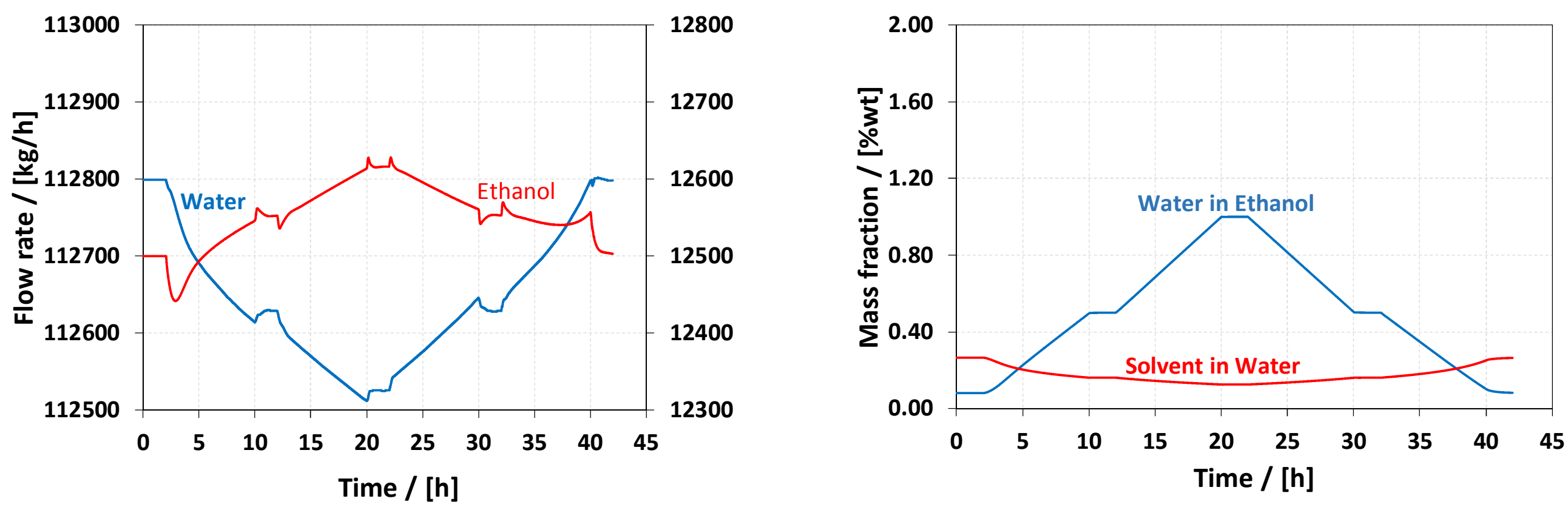

Figure 9 


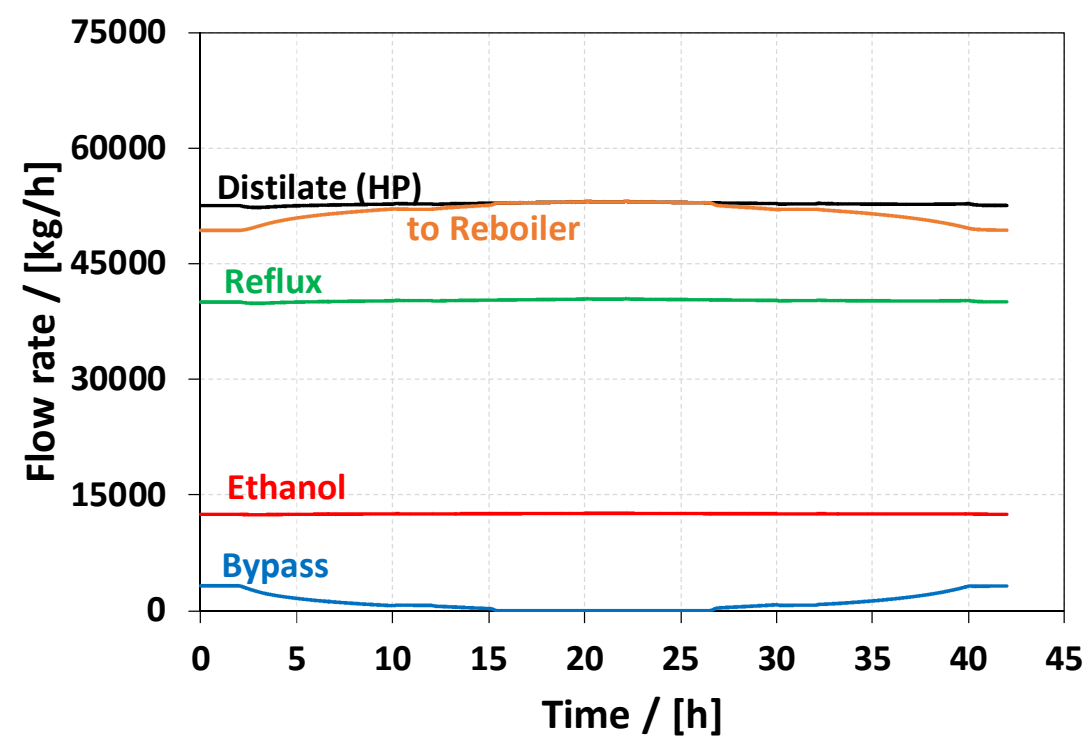

(a)
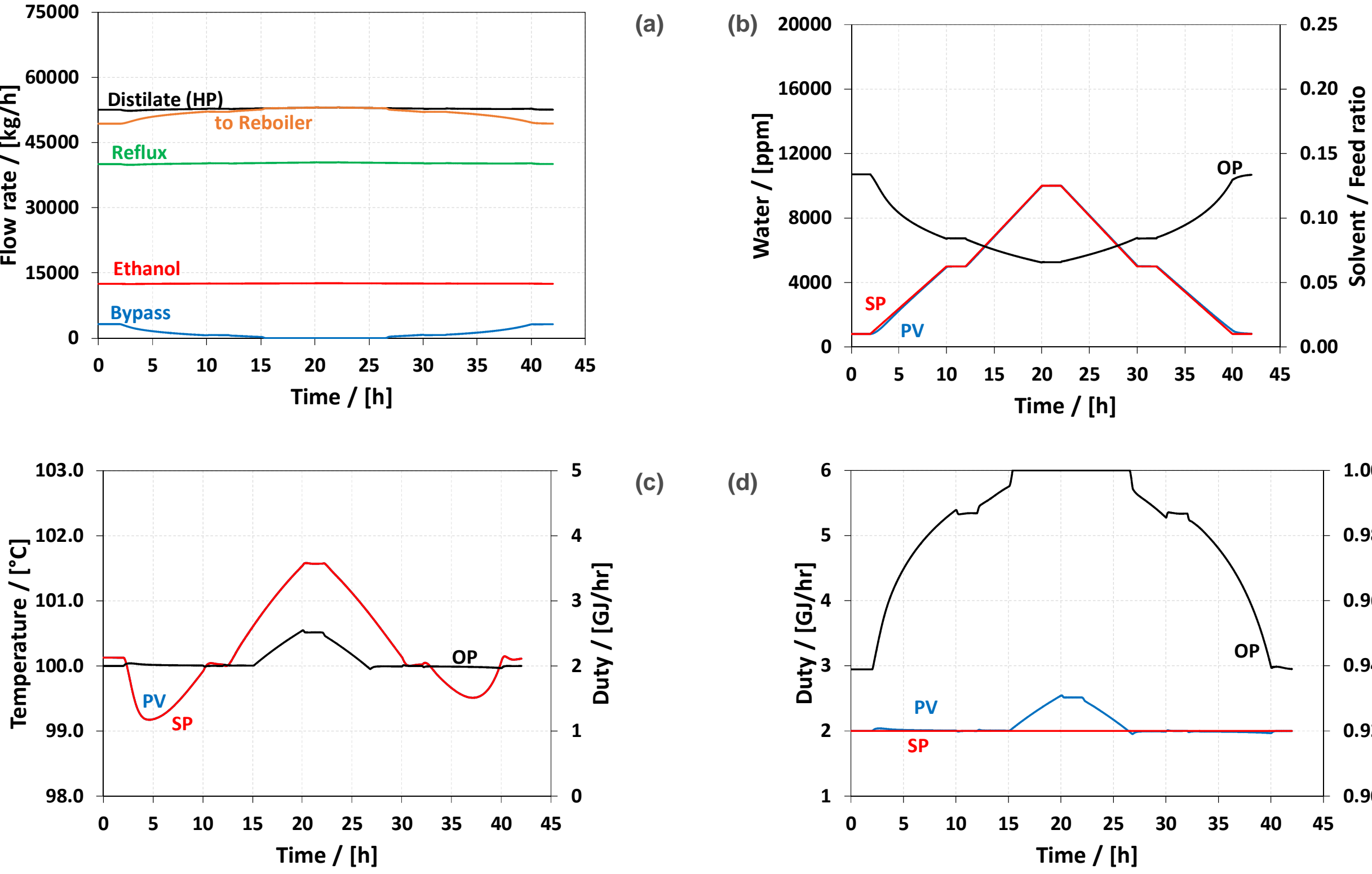

(c)
(d)

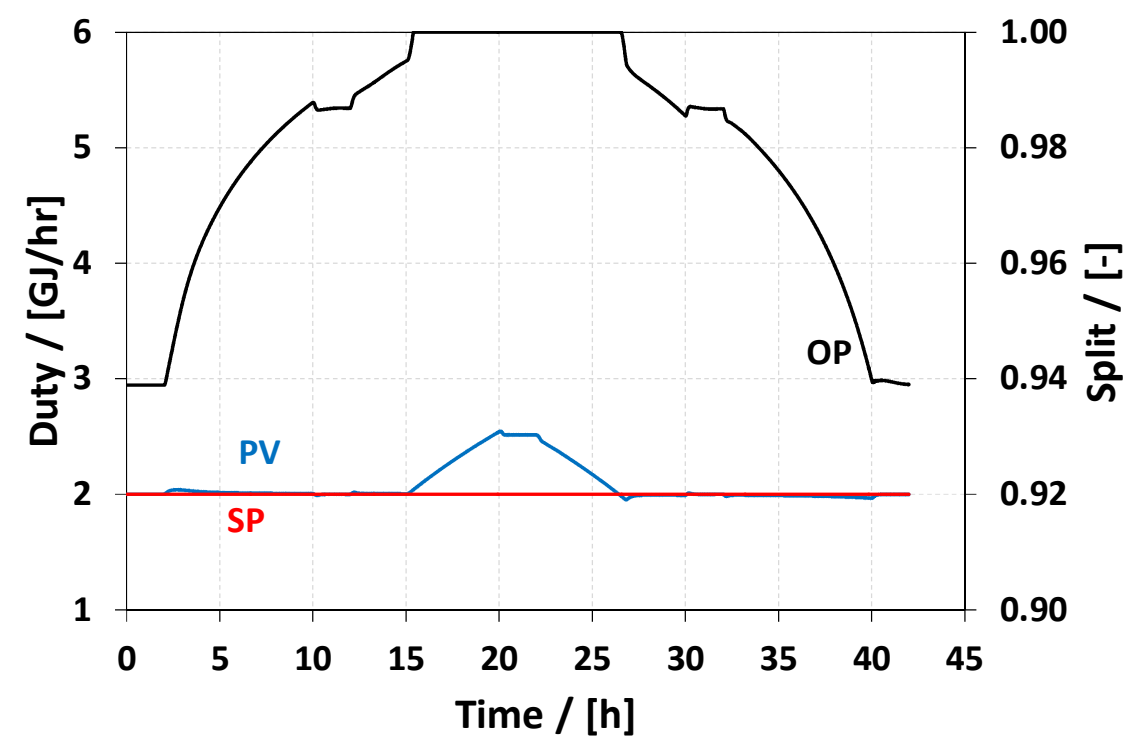

Figure 10 